\title{
Stock Market Efficiency and Integration: A Study of Eight Economies in the Asia-Pacific Region
}

\author{
Dimuthu Samaratunga ${ }^{1}$
}

\begin{abstract}
A stock market is considered to be efficient if it accurately reflects all the relevant information in determining security prices. In international stock markets, if the assets with identical risks offer similar level of expected returns, then markets are said to be integrated.

This paper investigates the stock market efficiency and integration of eight selected economies in the Asia-Pacific region. The sample is composed of 4 Emerging/ Developing (Sri Lanka, China, Malaysia and Pakistan) and 4 Developed (Australia, Hong Kong, Japan and Singapore) markets. The motivation of this paper is two-fold. The first objective is to investigate whether the selected stock markets are efficient at individual level, while the second is to examine whether international diversification is effective.

The results revealed that there is no evidence against the efficiency of Japan's stock market while markets of Sri Lanka, Pakistan and Australia are proved to be inefficient. For China, Malaysia, Hong Kong and Singapore, the tests gave inconclusive results with regard to market efficiency. The cointegration analysis confirmed that there are no long-run co-movements between the stock prices, and thus international diversification within economies in the sample is effective.
\end{abstract}

\footnotetext{
${ }^{1}$ This paper is an outcome of a continuation of the initial research conducted by the author for her Masters dissertation at University of Warwick, UK. The author is grateful to Dr. Xing Jin, her supervisor at Warwick, for his valuable comments and technical support rendered, and also wishes to thank Mr. W.A. Wijewardane, Deputy Governor, Dr. D. S. Wijesinghe, Assistant Governor and Dr. P N Weerasinghe, Director, Economic Research Department, Mr. Anil Perera, Ms. Erandi Liyanage and Ms. Kaushalya Subasinghe, all of Central Bank of Sri Lanka, for their advice, encouragement and support in publishing this paper.
} 


\section{Introduction}

The equity market of a country plays a prominent role in its economic development. It not only encourages savings and investments in the economy, but also enhances corporate governance and social responsibility. Despite the fact that the stock market is a relatively risky mode of investment, it provides greater opportunity for local and global diversification through effective and efficient asset allocation.

A market is considered to be efficient if it fully and correctly reflects all available information in determining stock prices which is referred to as the Efficient Market Hypothesis (EMH) (Fama, 1970). Random walks in stock returns are crucial to the formulation of rational expectation models and testing of the weak form market efficiency (where the current price is assumed to reflect all information included in the past prices). Since the stock prices in an efficient market incorporate all relevant information, the stock returns should display an unpredictable behaviour. On the contrary, if stock returns are predictable, there will be distortions in the pricing of capital and risk, which will ultimately curtail the economic development of the country (Worthington and Higgs, 2003).

In the global scenario, the deregulation and liberalisation of financial markets have led the investors to pay more attention to the international securities markets. If assets of identical risk in different countries lead to a similar level of expected return, then markets are said to be integrated. In modern portfolio theory, the main theme advocates investors to diversify their assets across national borders, as long as returns to stock in the other markets are less than perfectly correlated with the domestic market (Lim, Lee and Liew, 2003). This implies that when the markets are cointegrated, the benefits of international diversifications are not maximised and thus arbitrage profits could be explored.

Based on the above rationalizations, this paper aims to test two objectives: firstly, the equity market efficiency, and secondly, the effectiveness of international diversification of eight economies (China, Malaysia, Pakistan, Sri Lanka, Australia, Hong Kong, Japan and Singapore) in the Asia-Pacific region. Among these stock markets, three markets have secured places in the world's top 10 stock exchanges in terms of Market Capitalisation (as of end 2007) where Japan, China and Hong Kong were ranked second, sixth and seventh respectively. Provided that these markets are ranked among the top, it is worthwhile to find out whether they are individually efficient. Moreover, in the global context, it is of greater interest to investigate whether they give the investors the opportunity for effective international diversification.

The remainder of the paper is organised as follows: Section 2 summarises the 'Literature Review', while Section 3 provides the 'Description and Properties of Data'. Section 4 includes the 'Methodology'. 'Empirical Results' are reported in Section 5 while Section 6 summarises the 'Conclusions' of the study. 


\section{Literature Review}

Lo and MacKinlay (1988) have tested the Random Walk Hypothesis (RWH) for stock market returns by comparing variance estimators derived from data sampled at weekly and monthly frequencies. The RWH was strongly rejected for the entire sample period (1962-1985) and all sub periods for a variety of aggregate returns indices and size sorted portfolios. Although the rejections were due largely to the behaviour of small stocks, they could not be attributed completely to the effects of infrequent trading or time-varying volatilities. As per Lo and MacKinlay (1988), the patterns of rejections of the random walk indicated that the stationary mean-reverting models of earlier researches (example, Shiller and Perron (1985) and Summers (1986)) could not account for the departures of weekly returns from the random walk.

Fama (1970) has reviewed the theoretical and empirical literature on the EMH. The empirical evidence was divided into the three categories of market efficiency depending on the information subset of interest. Strong form tests were concerned with whether individual investors or groups had monopolistic access to any information relevant for price information. In the less restrictive semi-strong form tests, the information subset of interest included all obviously publicly available information, while in the weak form tests, the information subset was just historical prices. Fama (1970) used daily prices for each of thirty stocks of the Dow Jones Industrial Average for the period 1957-1962 and found that the results of the weak form tests of the efficient market were strongly in support of market efficiency. Though there was evidence of autocorrelations, some of which were consistent with the fair game model while the rest did not appear to be sufficient to declare market inefficiency, (Fama, 1970).

The earlier studies on market efficiency had revealed that EMH holds true (with very few exceptions) in most of the markets, such as New York, Australia and London. However, as better data sources (daily stock price data) and more sophisticated econometric methods for data analysis became available, it was later revealed that there are inconsistencies in the past findings, (Jensen, 1978). These anomalies were significant that they could not be neglected. Ball (1978) (as quoted by Jensen, 1978) has found that, as a whole the pieces of scattered evidence stack up in a manner which make a much stronger case for the necessity to carefully review both the acceptance of the EMH and the methodological procedures. To overcome the above issue, in this particular study, more sophisticated test statistics such as LJung-Box Q-statistic, Variance Ratio test and accurate data series are used. Fama (1997) too has suggested that anomalies could be due to methodology and most long-term anomalies tend to disappear with reasonable advancement in technique.

Similar to Jensen's (1978) study, Schwert (2003) has carried out a research on anomalies and market efficiency, which raised the question of whether profit opportunities existed in the past, but has since been arbitraged away, or whether the 
anomalies were simply statistical aberrations that attracted the attention of academics and practitioners. The study revealed that the size effect, the value effect, weekend effect and the dividend yield effect seem to have disappeared after the papers that highlighted them were published.

Worthington and Higgs (2003) have examined the market efficiency of 10 emerging and 5 developed equity markets in Asia. They have found that none of the emerging markets in their study (China, India, Indonesia, Korea, Malaysia, Pakistan, Philippines, Sri Lanka, Taiwan, Thailand) could be characterised by random walks, and thus those markets were inefficient. Among the developed markets in the study, the stock markets of Hong Kong, New Zealand and Japan were consistent with the most stringent random walk criteria, while Australia and Singapore did not prove to be efficient. A similar study has been carried out by Claessens, Dasgupta and Glen (1995) on the twenty emerging stock markets represented in the International Finance Corporation. They have found evidence for return predictability in all the markets and thus concluded those markets were inefficient.

Chan, Gup and Pan (1997) have carried out a study on 18 international markets to investigate the weak form market efficiency and to check whether those markets are cointegrated. In testing for cointegration, 7 sub-groups were formed depending on their common features such as geographic and economic standings. Their results have revealed that, on individual basis, all markets were efficient, while a small number of stock markets were cointegrated with others. Since the majority of the stock markets in the sample were not cointegrated and thus did not have long-run co-movements, they concluded that international diversification among the selected stock markets could be effective.

A similar study has been carried out by Lim, Lee, and Liew (2003), to examine the stock market integration in the ASEAN region, using a non-parametric cointegration test, called the Bierens's (1997) test. The results have indicated that there is a common force which brings all the five ASEAN stock markets together in the long run and the shocks from any of these five markets may spillover to the other markets in the same region. Thus, they have concluded that international diversification within the ASEAN was ineffective.

\section{Description and Properties of Data}

The set of data employed in the study is composed of value weighted indices of 4 Emerging/Developing stock markets; China, Malaysia, Pakistan, Sri Lanka and 4 Developed stock markets; Australia, Hong Kong, Japan and Singapore, in the AsiaPacific region. All the data are obtained from the EconStat and the most representative share price index of each country is used as the price data series. Moreover, in compliance with Lo and MacKinlay (1988), (where they analysed weekly data to avoid issues of bid-ask spread, and infrequent (non-synchronous) trading and pricing), the data 
series chosen for this study are weekly price indices. Each data series has its own sampling period, where the start date varies depending on the availability of that country's index. However, the end date for all indices is the same, i.e.16 May 2008. It is worth noting that varying sample periods do not affect the EMH conclusions as market efficiency is tested individually. In the cointegration analysis, the varying sample periods of the countries were matched to create a common sampling period that spread from 11 July 1997 to 16 May 2008. For the purpose of analysis, log returns were constructed, i.e. first, log price was obtained and the returns were derived as: $\mathrm{Rt}=\ln (\mathrm{Pt})$ $-\ln (\mathrm{Pt}-1)$.

Charts A1-A8 (in Annexure) present the distribution patterns of the weekly returns of each country in the study. Australia records the most stable weekly returns. Returns of Japan and China are dispersed over a narrow spread compared to the rest of the countries indicating stable stock returns. Malaysia, Hong Kong and Singapore show a relatively stable return pattern except for the high volatility during 1997-1998 period, signifying the impact of Asian currency crisis. Pakistan stock returns are the most volatile among the eight countries in the sample while Sri Lanka's stock market is relatively stable except for a few ad hoc shocks in 2001 and 2003.

It can be observed from the descriptive statistics presented in Table 1, that the distributions in the weekly returns of all eight countries have zero means (at two decimal places), with standard deviations varying between 0.02 and 0.04 . Australia has the lowest standard deviation, indicating a relatively stable return distribution over the 20 years.

Table 1: Descriptive Statistics

\begin{tabular}{lcccccccc}
\hline Description & China & Malaysia & Pakistan & Sri Lanka & Australia & H.Kong & Japan & Singapore \\
\hline Mean & 0.00 & 0.00 & 0.00 & 0.00 & 0.00 & 0.00 & 0.00 & 0.00 \\
Median & 0.00 & 0.00 & 0.01 & 0.00 & 0.00 & 0.00 & 0.00 & 0.00 \\
Maximum & 0.13 & 0.25 & 0.13 & 0.18 & 0.06 & 0.14 & 0.11 & 0.20 \\
Minimum & -0.08 & -0.19 & -0.18 & -0.10 & -0.35 & -0.42 & -0.13 & -0.26 \\
Std. Deviation & 0.03 & 0.03 & 0.04 & 0.03 & 0.02 & 0.04 & 0.03 & 0.03 \\
Skewness & 0.41 & 0.19 & -0.79 & 0.67 & -4.50 & -1.97 & -0.27 & -0.55 \\
Kurtosis & 4.43 & 10.83 & 5.69 & 7.86 & 74.11 & 22.79 & 4.87 & 13.11 \\
Jarque-Bera & 55.58 & 1799.41 & 209.11 & 547.64 & 254740.70 & 18052.13 & 192.11 & 4368.27 \\
P-Value & 0.00 & 0.00 & 0.00 & 0.00 & 0.00 & 0.00 & 0.00 & 0.00 \\
Sharpe Ratio & 0.08 & 0.01 & 0.10 & 0.11 & 0.09 & 0.05 & 0.02 & 0.05 \\
\end{tabular}

Stock return distributions of China, Malaysia and Sri Lanka are slightly positively skewed indicating the absence of high frequencies of higher returns (i.e. distributions are concentrated around low or negative returns). The rest of the countries have 
negatively skewed distributions, which indicate a greater probability of high or positive returns compared to low/negative returns. All eight distributions report a kurtosis coefficient greater than 3 , indicating leptokurtic distributions with many extreme observations. The zero p-values of Jarque-Bera test statistic indicate that the return distributions do not approximate the normal distributions for any country

The Shape ratio, as measured by mean returns over standard deviation is an indicator of relative risk-return trade off in each market. This measure is useful in comparing the effectiveness of international stock markets. It can be seen that Sri Lanka accounts for the highest Sharpe ratio followed by Pakistan. Since the investors tend to be cautious in developing markets, the risk return trade off is believed to be high in those markets. On the contrary, the developed markets, Japan, Singapore and Hong Kong report relatively low Sharpe Ratios. The Mean-Variance Frontier, which depicts the position of the stock returns against the standard deviations, is presented in Chart 1. It can be observed that only Sri Lanka has an above average mean return and a below average standard deviation, indicating a satisfactory risk-return trade off among the eight countries in the study.

Chart 1: Mean-Variance Frontier

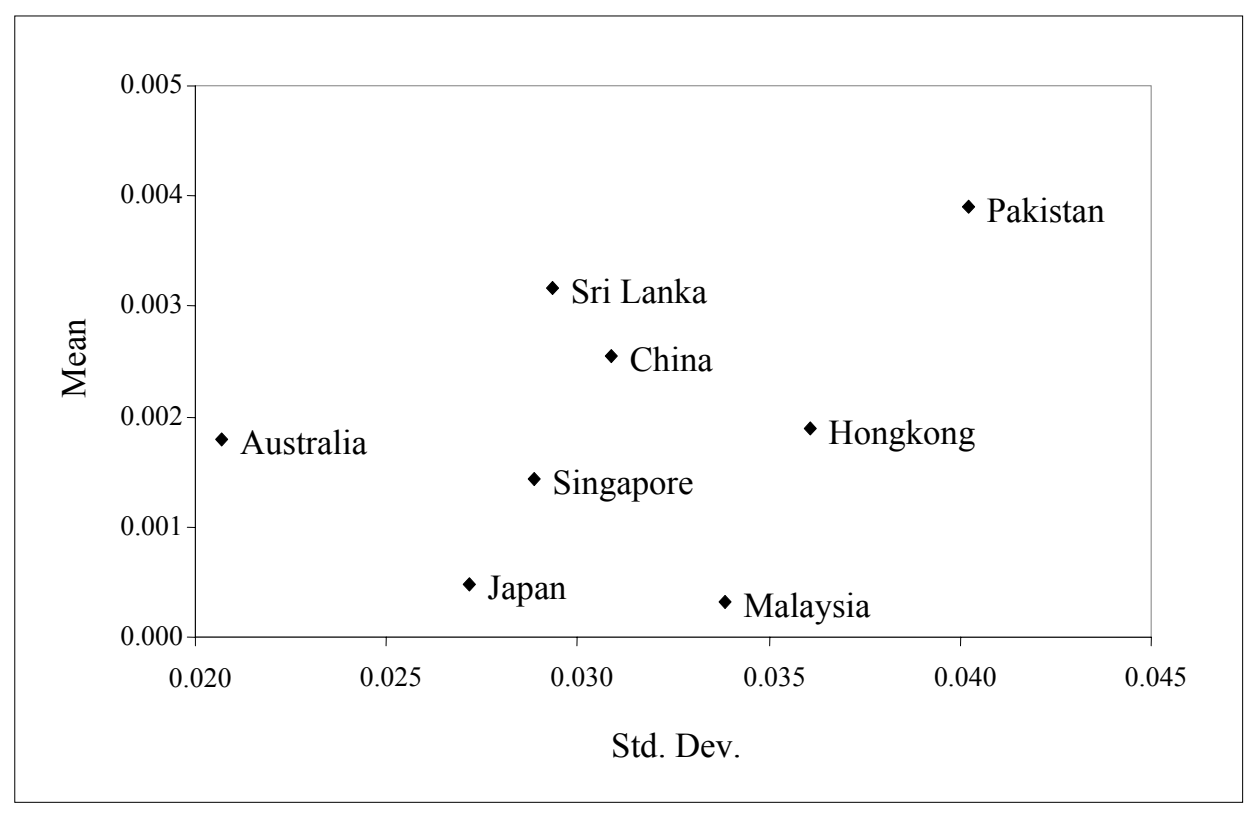




\section{Methodology}

In this study, several parametric and non-parametric tests are used to investigate whether the stock returns are weak-form efficient, while the cointegration between the international markets is tested using the Vector Autoregression (VAR) models. A description of these tests and their suitability for application are briefed below.

\subsection{Random Walk Hypothesis (RWH)}

As stated above, an asset market is said to be efficient if the asset prices fully reflect all the available information. Thus in an efficient market, price changes are a result of the arrival of new information. Since information arrives randomly, fluctuations in share prices would be unpredictable. Under the RWH, the market exhibits a weak form as the most recent price contains all the available information and therefore the best predictor of the future price. Further, there will be no autocorrelation as the disturbance term cannot process any systematic forecast errors (Worthington, 2003).

There are 3 versions of the RWH, namely, Random Walk 1 (RW1), Random Walk 2 (RW2), and Random Walk 3 (RW3). RW1, the most restrictive version of the Random Walk Model (RWM) states that errors are independently and identically distributed with mean, zero and variance, $\sigma^{2}$, and thus the returns will be serially uncorrelated, indicating the unpredictability of future price movements or volatility based on the past prices. RW2 is a relaxed version of RW1, where errors are independent but not identically distributed. This allows for unconditional heteroskedasticity, which is particularly a useful feature given the time-variation in volatility of many financial asset return series (Campbell et al., 1997). RW3, the least restrictive form of RWM, states that errors are serially uncorrelated and thus allows for dependence of higher moments.

\subsection{Unit Root Test}

Unit root test is used to test for non-stationarity as a necessary condition for RW2, (Worthington and Higgs, 2003). According to the RWH, the log price series should have a unit root while the returns series should be stationary. Three methods of unit root tests, namely, the Augmented Dickey Fuller (ADF) (1979), the Phillips-Perron (PP) (1988) and Kwiatkowski, Phillips, Schmidt and Shin (KPSS) (1992) are used on log price indices as well as on returns. 
ADF test (with constant and deterministic tend) has the following form:

$$
\Delta Y_{t}=\mu+\beta t+\alpha Y_{t-1}+\sum_{k=1}^{p} c_{k} \Delta Y_{t-k}+\varepsilon_{t}
$$

The null hypothesis $(\alpha=0)$ indicates that the series has a unit root, whereas under the alternative hypothesis $(\alpha<0)$, the series is stationary.

PP test is a non-parametric test, which modifies the ADF test statistic such that its asymptotic distribution is unaffected by the serial correlation. Both these tests are used as it will permit to overcome the ambiguity that ADF test has limited power in finite samples to reject the null hypothesis of non-stationarity. The KPSS is a parametric test, with a null hypothesis of 'stationary series' which is opposed to the null of both ADF and PP tests.

\subsection{Autocorrelation Function (ACF) and LJung-Box Q- Statistic Test}

The significance of ACF at each lag can be tested using the method recommended by Brooks (2002), where the critical value is calculated as $2 / \sqrt{T}$, where $\mathrm{T}$ is the number of weekly observations.

The LJung-Box Q-Statistic test is a parametric test that is used to find out whether the returns are linearly independent. i.e. it tests the joint significance of the first $\mathrm{m}$ ACFs. The test statistic takes the following form:

$$
Q(m)=T(T+2) \sum_{k=1}^{m}\left(\rho_{k}^{2} /(T-k)\right) \rightarrow \chi^{2}(m)
$$

If results reveal there is no autocorrelation, then the return series is assumed to follow a random walk (RW1).

\subsection{Variance Ratio (VR) Test (Lo and MacKinlay, 1988)}

VR test statistic takes the following form:

$$
\operatorname{VR}(q)=\operatorname{var}(r,(q)) / q \operatorname{var}(r)=1+2 \sum_{k=1}^{q-1}(1-(k / q)) \rho_{k}
$$

This non-parametric test could be used only when the returns are homoskedastic and it allows checking for RW1. Under the null hypothesis, the VR statistic must be equal to 1 . If VR exceeds 1 , then there exists positive serial correlation whereas if it's less than 1, the returns are negatively correlated. Further, as per Campbell et al. (1997), 
if the variance of random walk increments is a linear function of time interval, then the RWH holds.

The Standardized VR test statistic takes the form:

$$
\phi(q)=(\operatorname{VR}(q)-1)(2(2 q-1)(q-1) / 3 T q)^{-1 / 2} \rightarrow N(0,1)
$$

\subsection{Heteroskedastic-Robust Standardized Variance Ratio (VR) Test}

When errors are serially uncorrelated, the heteroskedastic-robust standardized VR test can be used to test for RW2 and RW3, which takes the following form:

$$
\phi^{*}(q)=\sqrt{T(V R(q)-1)} \theta(q)^{-1 / 2} \rightarrow N(0,1)
$$

\subsection{Cointegration Analysis}

Cointegration analysis will be carried out to examine whether there exist any long-run cointegrating relationship between the $(\log )$ price series of the countries, using the Vector Autoregression (VAR) in Johansen's Maximum Likelihood (Johansen's ML) estimation procedure, (Johenson, 1988; Johenson and Juselius, 1990). Accordingly the VAR of order $\mathrm{k}$ for $\log$ price $(\mathrm{Y})$ is represented in error correction form as follows:

$$
\Delta Y_{t}=\sum_{i=1}^{k} \Gamma_{i} \Delta Y_{t-i}+\Pi Y_{t-k}+\varepsilon_{t}
$$

Where: $\quad \Gamma \mathrm{i}=(\Pi 1+\ldots . .+\Pi \mathrm{i}-\mathrm{I})$

$$
\Pi=(\Pi 1+\ldots \ldots+\Pi \mathrm{k}-\mathrm{I})
$$

The rank (r) of the long-run matrix (П), determines the number of cointegrating vectors in the system, where, $r$ takes any value between 0 and the number of countries in the group (n). The tests used to obtain $r$ are, the Maximum eigenvalue test $\left(\lambda_{\text {Max }}\right)$ and Trace $\left(\lambda_{\text {Trace }}\right)$ tests. $\lambda$ Trace tests whether the smallest $n-r$ estimated eigenvalues are significantly different from zero, while $\lambda_{\text {Max }}$ test whether the estimated $(r+1)$ th largest eigenvalue is significantly different from zero.

Maximum eigenvalue statistic for H0: $\operatorname{rank} \leq r$, Vs. H1: rank $=r+1$ is given by:

$$
\lambda_{\text {Max }}(r, r+1)=-T \ln \left(1-\lambda_{r+1}\right)
$$


Trace statistic for H0: rank $\leq \mathrm{r}$, Vs. H1: rank $\geq \mathrm{r}+1$ is given by:

$$
\lambda_{\text {Trace }}(r)=-T \sum_{i=r+1}^{n} \ln \left(1-\lambda_{i}\right)
$$

\subsection{Short-run Dynamics}

In the event that a long-term cointegrating relationship between the international stock prices does not exist, analysing the short-run dynamics would give an indication of the short term impact of markets on each other. This would be tested using the impulse response analysis, variance decomposition and Granger causality tests under the VAR. Impulse response analysis traces out the responsiveness of the dependent variable in the VAR to shocks of each of the other variables in the sample while variance decomposition gives the proportion of movements in the dependent variable that is due to its own shocks against the shocks to the other variables. Granger causality test determines whether a particular stock price series is useful in forecasting another.

Note: Unit Root tests, LJung-Box Q-Statistic tests and VAR (including impulse response analysis, variance decomposition and Granger causality test) is performed on Eviews 5 while Matlab 7.0.1 will be used to carry out the VR tests.

\section{Empirical Results}

\subsection{Unit Root Tests}

Results of the unit root tests are presented in Table 2. The ADF and PP test the null hypothesis of non-stationarity (i.e. the series has a unit root) against the alternative of stationarity. At levels, the test statistics of both ADF and PP for all eight countries do not reject the null hypothesis at 5\% significance level, which indicate that log price series are non-stationary. However, at differences, both tests indicate that returns series of all countries are stationary at 5\% level. The null of no unit root in KPPS is rejected at levels series, indicating that log prices are non-stationary. Further, the null of stationarity in the difference series is not rejected at $5 \%$ level, signifying that returns series of all eight countries are stationary. The necessary condition for RWH to hold is that price series should be non-stationary, while the returns series be stationary. From the results of the ADF, PP and KPSS above, it can be seen that log prices of all countries are non-stationary and thus it can be said that there is no evidence against weak form efficiency in all the eight markets. However, it is known that the above tests for unit roots have a lower power and therefore it is imperative that the weak form efficiency be tested using more sophisticated test statistics. 
Table 2: Unit Root Test Results

\begin{tabular}{lccccccccc}
\hline \multirow{2}{*}{ Test } & Indicator & China & Malaysia & Pakistan & Sri Lanka & Australia & H.Kong & Japan & Singapore \\
\hline \multirow{2}{*}{ ADF - Levels } & Statistic & 1.20 & -1.38 & 0.51 & 0.38 & -1.09 & -1.31 & -1.77 & -1.80 \\
& P-Value & 1.00 & 0.59 & 0.99 & 0.98 & 0.72 & 0.62 & 0.39 & 0.38 \\
ADF - Differences & Statistic & $-20.81^{*}$ & $-25.46^{*}$ & $-18.99^{*}$ & $-19.09^{*}$ & $-28.35^{*}$ & $-29.85^{*}$ & $-35.76^{*}$ & $-30.35^{*}$ \\
& P-Value & 0.00 & 0.00 & 0.00 & 0.00 & 0.00 & 0.00 & 0.00 & 0.00 \\
\multirow{2}{*}{ PP - Levels } & Statistic & 0.61 & -1.88 & 0.80 & 0.37 & -1.10 & -1.30 & -1.81 & -2.06 \\
& P-Value & 0.99 & 0.34 & 0.99 & 0.98 & 0.72 & 0.63 & 0.38 & 0.26 \\
PP - Differences & Statistic & $-21.12^{*}$ & $-25.98^{*}$ & $-19.05^{*}$ & $-19.18^{*}$ & $-28.40^{*}$ & $-29.91^{*}$ & $-35.76^{*}$ & $-30.60^{*}$ \\
& P-Value & 0.00 & 0.00 & 0.00 & 0.00 & 0.00 & 0.00 & 0.00 & 0.00 \\
KPSS - Levels & Statistic & $0.48^{*}$ & $0.51^{*}$ & $2.66^{*}$ & $2.43^{*}$ & $4.16^{*}$ & $3.42^{*}$ & $1.54^{*}$ & $1.33^{*}$ \\
& 5\% C.V. & 0.46 & 0.46 & 0.46 & 0.46 & 0.46 & 0.46 & 0.46 & 0.46 \\
KPSS - Differences & Statistic & 0.33 & 0.17 & 0.43 & 0.42 & 0.07 & 0.06 & 0.27 & 0.11 \\
& 5\% C.V. & 0.46 & 0.46 & 0.46 & 0.46 & 0.46 & 0.46 & 0.46 & 0.46
\end{tabular}

\subsection{Autocorrelations and LJung-Box Q-Statistic}

Table A1 and A2 (in Annexure) illustrate the ACF and the LJung-Box Q-Statistic for the Emerging / Developing and Developed countries respectively.

It can be seen that the first order ACFs for Pakistan and Sri Lanka, and both first and second order ACF for Australia and Hong Kong are positive and statistically significantly different from zero. This indicates that there exist positive serial correlations between the current and previous week's stock returns for Pakistan and Sri Lanka, while current and previous two weeks returns for Australia and Hong Kong. Thus those markets are inefficient. The first order ACF of Japan is negative while its ACFs at all lags are insignificant. This implies that there is no evidence against Japan's market efficiency. For China, Malaysia, and Singapore, the results are rather vague, where the first and second order ACFs are insignificant, but higher order ACFs appears to be significant.

If the P-value of the Q-Statistic is less than 0.05 , then null of all autocorrelation coefficients jointly equal to zero can be rejected at $5 \%$ significant level, and it can be concluded that past returns could be used to predict future returns, and thus weak form market efficiency does not hold. The P- values in Table A1 and A2 (in Annexure) show that China, Malaysia and Singapore give ambiguous results, having significant Qstatistics in-between the lags. In Pakistan, Sri Lanka, Australia and Hong Kong, the null 
hypothesis can clearly be rejected and thus RW1 does not hold and the markets are inefficient. The Q-statistic of Japan is not significant at all lags, which indicates that there is no serial correlation. This implies that there is no evidence against weak form efficiency for Japan's stock returns. However, these conclusions should further be verified using the more advanced Variance Ratio test.

\subsection{Variance Ratio (VR) Test}

Table 3 presents the results of the VR tests for the lags (q) 2, 4, 8, and 16 respectively. It can be observed that VR test statistic increases as q increases in all the eight countries. 
$\underline{\text { Stock Market Efficiency and Integration: A Study of Eight Economies in the Asia-Pacific Region }}$

Table 3: Variance Ratio Test Results

\begin{tabular}{|c|c|c|c|c|}
\hline \multirow{2}{*}{$\begin{array}{l}\text { Country / } \\
\text { Statistic }\end{array}$} & \multicolumn{4}{|c|}{ Number $q$ of base information aggregated to form $V R$} \\
\hline & 2 & 4 & 8 & 16 \\
\hline \multicolumn{5}{|l|}{ China } \\
\hline VR & 1.06 & 1.23 & 1.45 & 1.71 \\
\hline$\Phi(q)(R W 1)$ & 1.39 & $2.70^{*}$ & $3.36^{*}$ & $3.56^{*}$ \\
\hline$\Phi^{*}(\mathrm{q})(\mathrm{RW} 2 \& \mathrm{RW} 3)$ & 1.16 & $2.30 *$ & $2.89^{*}$ & $3.20^{*}$ \\
\hline \multicolumn{5}{|l|}{ Malaysia } \\
\hline VR & 1.04 & 1.16 & 1.38 & 1.59 \\
\hline$\Phi(q)(R W 1)$ & 1.07 & $2.22 *$ & $3.40 *$ & $3.56^{*}$ \\
\hline$\Phi^{*}(\mathrm{q})(\mathrm{RW} 2 \& \mathrm{RW} 3)$ & 0.72 & 1.43 & $2.12 *$ & $2.22 *$ \\
\hline \multicolumn{5}{|l|}{ Pakistan } \\
\hline VR & 1.18 & 1.36 & 1.40 & 1.46 \\
\hline$\Phi(\mathrm{q})(\mathrm{RW} 1)$ & $4.05^{*}$ & $4.33^{*}$ & $3.04 *$ & $2.35^{*}$ \\
\hline$\Phi^{*}(\mathrm{q})(\mathrm{RW} 2 \& \mathrm{RW} 3)$ & $3.35 *$ & $3.64 *$ & $2.51 *$ & $1.97 *$ \\
\hline \multicolumn{5}{|l|}{ Sri Lanka } \\
\hline VR & 1.17 & 1.34 & 1.49 & 1.55 \\
\hline$\Phi(\mathrm{q})(\mathrm{RW} 1)$ & $3.96^{*}$ & $4.13 *$ & $3.75^{*}$ & $2.85^{*}$ \\
\hline$\Phi *(q)(R W 2 \& R W 3)$ & $3.12 *$ & $3.37 *$ & $3.14 *$ & $2.33 *$ \\
\hline \multicolumn{5}{|l|}{ Australia } \\
\hline VR & 1.19 & 1.39 & 1.46 & 1.45 \\
\hline$\Phi(q)(R W 1)$ & $6.71 *$ & $7.13 *$ & $5.37 *$ & $3.44 *$ \\
\hline$\Phi^{*}(\mathrm{q})(\mathrm{RW} 2 \& \mathrm{RW} 3)$ & $4.55^{*}$ & $5.21 *$ & $3.86^{*}$ & $2.50 *$ \\
\hline \multicolumn{5}{|l|}{ Hong Kong } \\
\hline VR & 1.09 & 1.19 & 1.21 & 1.23 \\
\hline$\Phi(q)(R W 1)$ & $2.90 *$ & $3.35^{*}$ & $2.28 *$ & 0.95 \\
\hline$\Phi *(q)(\mathrm{RW} 2 \& \mathrm{RW} 3)$ & $2.27 *$ & $2.78 *$ & 1.89 & 0.78 \\
\hline \multicolumn{5}{|l|}{ Japan } \\
\hline VR & 0.98 & 1.03 & 1.10 & 1.16 \\
\hline$\Phi(q)(R W 1)$ & -0.83 & 0.59 & 1.13 & 1.27 \\
\hline$\Phi *(q)(R W 2 \&$ RW3) & -0.71 & 0.49 & 0.93 & 1.07 \\
\hline \multicolumn{5}{|l|}{ Singapore } \\
\hline VR & 1.05 & 1.15 & 1.27 & 1.41 \\
\hline$\Phi(q)(R W 1)$ & 1.53 & $2.61 *$ & $2.86^{*}$ & $2.93 *$ \\
\hline$\Phi^{*}(\mathrm{q})(\mathrm{RW} 2 \& \mathrm{RW} 3)$ & 1.19 & 1.87 & 1.89 & $2.01 *$ \\
\hline
\end{tabular}

* Significant at $5 \%$ level 
According to Lo and MacKinlay (1988), if the VR test statistic exceeds unity, then the return series is said to be positively correlated. This holds true for all countries except Japan, where the VR takes value 0.9763 . In the case of $q=2$, the VR test statistic minus one (i.e. VR - 1) returns the value of ACF, which can be verified with the ACF results of Section 5.2 above (Table A1 and A2 in Annexure). For example, the VR for China is 1.0625 , while Table A1 indicates that the ACF at lag 1 is $6.25 \%$. Likewise, it can be seen that Australia has the highest ACF of $19.44 \%$ followed by Pakistan (17.81\%) and Sri Lanka (17.41\%). Japan's VR of 0.9763 indicates its ACF is $-2.37 \%$. Thus it can be concluded that for Pakistan, Sri Lanka and Australia, the RWH does not hold while for Japan, it does.

The standardized VR test statistics $(\Phi(\mathrm{q}))$ is significant at all levels of $\mathrm{q}$ for Pakistan, Sri Lanka and Australia, and thus RW1 can be rejected at 5\% significance level. Further, these rejections are not due to the changing variances, as the heteroskedastic robust standardised VR test $\left(\Phi^{*}(\mathrm{q})\right)$ too is significant at all levels for above three countries, which permits to reject RW2 and RW3 as well. Another important observation is that in the above three countries, as VR increases with q, the $\Phi(\mathrm{q})$ and $\left.\Phi^{*}(\mathrm{q})\right)$ decreases. This indicates that as q increases, the significance of the rejection becomes weaker. In observing Japan, both $\Phi(\mathrm{q})$ and $\Phi^{*}(\mathrm{q})$ are not significant at all levels of q, indicating that RW1, RW2 and RW3 cannot be rejected at 5\% level. Therefore at $5 \%$ significance level, it can be concluded that there is no evidence against Japan's stock market efficiency, while for Pakistan, Sri Lanka and Australia, the RWH does not hold and hence inefficient.

The VR results of other four markets (China, Malaysia, Hong Kong and Singapore) are vague over the different levels of q. Considering China and Malaysia, it can be observed that at $\mathrm{q}=2$ level RWH holds, but from $\mathrm{q}=4$ onwards both $\Phi(\mathrm{q})$ and $\Phi^{*}(\mathrm{q})$ are rejected, implying that market is inefficient. In Hong Kong, RWH holds only at q=16. For Singapore, $\Phi(\mathrm{q})$ is significant at $\mathrm{q}=4,8$, and 16 , whereas $\Phi^{*}(\mathrm{q})$ is only marginally significant at q=16, which implies the rejection of RWH at each level is due to changes in variances. Owing to these ambiguous results, a definite conclusion regarding the market efficiency cannot be reached for China, Malaysia, Hong Kong and Singapore.

However, it is worth noting that rejecting or not rejecting the RWH does not necessarily imply that the markets are inefficient or efficient respectively (Lo and MacKinlay, 1988), since the conclusions of this study are based on samples.

\subsection{Cointegration Analysis}

First, the unrestricted VAR is estimated to find the lag length, for which Akaike Information Criteria (AIC) and Schwaz Information Criteria (SIC) are used. Both AIC and SIC are minimised at level 2 and the residual serial correlation LM test confirms that there is no autocorrelation. Therefore, lag 2 is selected as the optimal lag length. 
The Johansen multivariate cointegration test is then performed on the log price series of the eight countries. The test results of all eight markets as presented in Table 4 indicate that both test statistics, $\lambda_{\text {Max }}$ and $\lambda_{\text {Trace }}$ are lower than the $5 \%$ critical value and hence not significant even at $\mathrm{r}=0$ level. Therefore, it can be concluded that at $5 \%$ significance level, there is no cointegration among the eight stock markets in the study.

Table 4: Cointegration Test Results - All Markets

\begin{tabular}{crrrr}
\hline Null Hypo & $\boldsymbol{\lambda}_{\text {Trace }}$ & $\mathbf{5 \%} \mathbf{C V}$ & $\boldsymbol{\lambda}_{\text {Max }}$ & $\mathbf{5 \% ~ C V}$ \\
\hline $\mathrm{r}=0$ & 152.92 & 159.52 & 43.98 & 52.36 \\
$\mathrm{r} \leq 1$ & 108.94 & 125.61 & 35.42 & 46.23 \\
$\mathrm{r} \leq 2$ & 73.52 & 95.75 & 25.00 & 40.07 \\
$\mathrm{r} \leq 3$ & 48.52 & 69.81 & 17.96 & 33.87 \\
$\mathrm{r} \leq 4$ & 30.55 & 47.85 & 15.85 & 27.58 \\
$\mathrm{r} \leq 5$ & 14.70 & 29.79 & 8.53 & 21.13 \\
$\mathrm{r} \leq 6$ & 6.17 & 15.49 & 5.75 & 14.26 \\
$\mathrm{r} \leq 7$ & 0.41 & 3.84 & 0.41 & 3.84 \\
\hline
\end{tabular}

However, it would give a more profound understanding if the countries with similar economies are grouped and analysed to see whether they are cointegrated at sub-group levels (Chan, Gup and Pan, 1997). Thus, two groups are formed, namely, Emerging/Developing (China, Malaysia, Pakistan and Sri Lanka) and Developed (Australia, Hong Kong, Japan and Singapore), and the same procedure is carried out to test for cointegration. The respective results are presented in Tables 5, (since there are 4 countries in each group, the maximum value $r$ can take is 3 ). Similar to the 'all-markets' analysis, both $\lambda_{\text {Max }}$ and $\lambda_{\text {Trace }}$ are less than $5 \%$ significance level for the sub-groups and thus it can be concluded that there is no cointegration in either of the groups. This implies that the stock markets of China, Malaysia, Pakistan and Sri Lanka in the Emerging/Developing group and Australia, Hong Kong, Japan and Singapore in the Developed group do not have long-run co-movements within their respective sub groups. Hence, the international diversification within 'all eight markets' as well as within 'sub groups' are effective. 
Table 5: Cointegration Test Results - Sub Groups

\begin{tabular}{|c|c|c|c|c|c|c|}
\hline \multirow[b]{2}{*}{ Null Hypo } & \multicolumn{2}{|c|}{$\begin{array}{c}\text { Four Emerging / } \\
\text { Developing Markets }\end{array}$} & \multicolumn{2}{|c|}{$\begin{array}{l}\text { Four Developed } \\
\text { Markets }\end{array}$} & \multicolumn{2}{|c|}{$5 \% \mathrm{CV}$} \\
\hline & $\lambda_{\text {Trace }}$ & $\lambda_{\text {Max }}$ & $\lambda_{\text {Trace }}$ & $\lambda_{\text {Max }}$ & $\lambda_{\text {Trace }}$ & $\lambda_{\text {Max }}$ \\
\hline $\mathrm{r}=0$ & 31.09 & 18.75 & 33.60 & 19.49 & 47.85 & 27.58 \\
\hline $\mathrm{r} \leq 1$ & 12.34 & 8.49 & 14.11 & 10.30 & 29.79 & 21.13 \\
\hline$r \leq 2$ & 3.85 & 3.82 & 3.81 & 3.81 & 15.49 & 14.26 \\
\hline$r \leq 3$ & 0.02 & - & 0.05 & - & 3.84 & 3.84 \\
\hline
\end{tabular}

\subsection{Short-run Dynamics}

Impulse response analysis reveals that when there is a shock of 1 standard deviation in the Malaysian market, it will impact China, Pakistan, Sri Lanka in the second week (at peak level) and then vanish gradually by the sixth week. This implies that even the short-term impacts disappear in about one and half months. However, the impacts of the shocks in China, Pakistan and Sri Lanka on rest of the markets are not significant. Even in developed markets, most impacts are insignificant and disappear after about 1 month.

Tables 6 summarises the results of the variance decomposition analysis. In China, Malaysia, Pakistan, Sri Lanka and Australia, even by end of the sixth month, around $95 \%$ of the variance comes from itself. This implies that sentiments about own markets have a dominant effect than the direct impacts form other markets in the sample. In Hong Kong $70 \%$ of the variance is due to its own variance while the rest comes from Australia. Similarly, in Japan $70 \%$ of the variance is due to its own shocks while around $26 \%$ comes from Australia and around 4\% from Hong Kong. However, in Singapore, $50 \%$ of variance is due to its own, while $24 \%$ comes from Australia and Hong Kong each followed by $2 \%$ from Japan. 
Stock Market Efficiency and Integration: A Study of Eight Economies in the Asia-Pacific Region

Table 6: Variance Decomposition Results Summary

\begin{tabular}{|c|c|c|c|c|c|}
\hline Country & Weeks & CHINA & MALAY & PKSTN & SL \\
\hline \multirow[t]{3}{*}{ China } & 1 & 100 & 0.00 & 0.00 & 0.00 \\
\hline & 12 & 97.57 & 1.45 & 0.52 & 0.45 \\
\hline & 24 & 97.57 & 1.45 & 0.52 & 0.45 \\
\hline \multirow[t]{3}{*}{ Pakistan } & 1 & 0.36 & 1.34 & 98.31 & 0.00 \\
\hline & 12 & 0.79 & 2.81 & 96.38 & 0.02 \\
\hline & 24 & 0.79 & 2.81 & 96.38 & 0.02 \\
\hline \multirow[t]{3}{*}{ Malaysia } & 1 & 0.35 & 99.65 & 0.00 & 0.00 \\
\hline & 12 & 0.44 & 99.04 & 0.31 & 0.21 \\
\hline & 24 & 0.44 & 99.04 & 0.31 & 0.21 \\
\hline \multirow[t]{3}{*}{ Sri Lanka } & 1 & 0.01 & 1.06 & 0.73 & 98.2 \\
\hline & 12 & 0.96 & 3.08 & 1.94 & 94.01 \\
\hline & 24 & 0.96 & 3.08 & 1.94 & 94.01 \\
\hline Country & Weeks & AUS & HK & JAPAN & SIN \\
\hline \multirow[t]{3}{*}{ Australia } & 1 & 100 & 0.00 & 0.00 & 0.00 \\
\hline & 12 & 99.41 & 0.28 & 0.06 & 0.25 \\
\hline & 24 & 99.41 & 0.28 & 0.06 & 0.25 \\
\hline \multirow[t]{3}{*}{ H.Kong } & 1 & 29.99 & 70.01 & 0.00 & 0.00 \\
\hline & 12 & 29.71 & 69.37 & 0.18 & 0.74 \\
\hline & 24 & 29.71 & 69.37 & 0.18 & 0.74 \\
\hline \multirow[t]{3}{*}{ Japan } & 1 & 26.16 & 3.6 & 70.24 & 0.00 \\
\hline & 12 & 26.03 & 3.62 & 70.02 & 0.33 \\
\hline & 24 & 26.03 & 3.62 & 70.02 & 0.33 \\
\hline \multirow[t]{3}{*}{ Singapore } & 1 & 24.35 & 23.76 & 1.12 & 50.77 \\
\hline & 12 & 24.16 & 23.97 & 1.74 & 50.13 \\
\hline & 24 & 24.16 & 23.97 & 1.74 & 50.13 \\
\hline
\end{tabular}

Granger causality test results presented in Table A3 (in Annexure) reveal that in the short-run (particularly in the second week), Malaysia Granger causes China and Sri Lanka while Hong Kong Granger causes Singapore at 5\% significance level. Rest of the markets do not have any influence on each other. 


\subsection{General Issues and Possible Extensions to the Study}

The results of this study revealed that only Japan's stock market is efficient. However, these results contradict with that of Worthington and Higgs's (2003) study. The discrepancies between the results of the two respective studies could possibly be due to different sampling periods and the structural changes that these markets have undergone within the chosen sampling periods.

Referring to market integration, Chan, Gup and Pan (1997) had found out that during the period 1980-1987, the Asian Stock markets were cointegrated, which contradicts with the results of this study. This may simply be due to the different sampling periods. Another reason could be that the impact of globalisation and advanced communication systems may have led to eliminate the long-run comovements among stock prices by the present day.

Since the stock returns distributions were found to be non-normal, using parametric tests on these data sets could give ambiguous results. Instead, if non-parametric tests such as Runs test, VR test based on signs and ranks are used, then unbiased results on market efficiency could be obtained.

Lo and MacKinlay (1988) had analysed the monthly stock return data and found that significance of rejection of RWH declines when moving from weekly returns to monthly returns. As an extension to this particular study, monthly data of the eight markets could be analysed to check whether they conform to Lo and Mackinlay's (1988) findings.

Another possible extension is 'sub-period-analysis'. It is a well known fact that with globalisation, the stock markets could easily be affected by global or regional economic shocks. If this study could be extended to incorporate sub periods, it would be possible to identify how major economic shocks such as the 1987- stock market crash, Asian financial crisis, September 11 etc, affected the market efficiency and integration.

It is a globally known fact that on Fridays stock returns are positive while returns on Mondays are negative. Since this implies predictability, the markets cannot be distinguished as weak form market efficient. Therefore, to find out the true impact, an extension for the analysis for 'weekend effect' would be more appropriate.

Finally, the collapse of the US sub-prime mortgage market and the aggravation of global financial turmoil in mid September 2008 have affected the stock markets around the world, resulting in high volatility in stock prices. Had the sampling period of the above study included data upto October 2008, the results and the subsequent conclusions might have been different. 


\section{Conclusion}

This paper investigates the stock market efficiency and integration of the eight selected economies in the Asia-Pacific region. The sample is composed of 4 Emerging/Developing (China, Malaysia, Pakistan and Sri Lanka) and 4 Developed (Australia, Hong Kong, Japan and Singapore) markets. The first motivation of the study is to investigate whether the selected stock markets are efficient at individual level, while the second is to examine whether international diversification is effective. If the markets are efficient individually, then no arbitrage profits could be made locally. Likewise, when international markets are not integrated, the arbitrage profit opportunities disappear and international diversification becomes effective.

The stock returns of each country were first examined individually to check for their conformity to Random Walk Hypothesis. The Unit Root test, LJung-Box QStatistic and Variance Ratio tests were employed for this analysis. The results revealed that Japan's equity market is weak-form efficient, while the stock markets of Sri Lanka, Pakistan and Australia are inefficient. This indicates that investors in Japan's stock market cannot systematically engage in profitable ventures while the predictability of stock returns in the markets of Sri Lanka, Pakistan and Australia gives investors the opportunity to explore arbitrage profits. Since the Autocorrelation, Q-Statistic and Variance Ratio test, give ambiguous results for the rest of the markets in the sample, no firm conclusion could be made on market efficiency for China, Malaysia, Hong Kong and Singapore.

The Johenson's cointegration test results on all markets (covering all eight economies) and two sub-groups (Emerging/Developing and Developed economies) indicate that there is no cointegration between the selected international equity markets. This implies that there are no long-run co-movements among the stock prices, and therefore, the investors with long-run horizons will benefit from investments made across the countries in the sample. Analysis of short-run dynamics revealed that the impact of markets in the sample on each other is insignificant. Hence, international diversification is effective. 


\section{References}

Brooks, C., 2002, Introductory Econometrics for Finance, 6th Edition, Cambridge University Press

Campbell, J.Y., Lo A.W. and MacKinlay A.C., 1997, The Econometrics of Financial Markets, 6th Edition, Princeton University Press

Chan, K., Gup, B., and Pan M., 1997, International Stock Market Efficiency and Integration: A Study of eighteen Nations, Journal of Business Finance and Accounting, 24(6), 803-813

Claessens, S., Dasgupta, S. and Glen, J., 1995, Returns Behaviour in Emerging Stock Markets, The World Bank Economic Review, Vol. 9, No.1:131-151

Fama, E., 1970, Efficient Capital Markets: A Review of Theory and Empirical Work, Journal of Finance 25, 383-417

Fama, E., 1997, Market Efficiency, Long-term Returns and Behavioural Finance, Journal of Financial Economics, Vol. 49, 283-306

Jensen, M. C., 1978, Some Anomalous Evidence Regarding Market Efficiency, Journal of Financial Economics, Vol. 6, 95-101

Laopodis, N.T., 2004, Financial market liberalization and stock market efficiency: Evidence from the Athens Stock Exchange, Global Finance Journal 15, 103-123

Lim, K., Lee, H., and Liew, K., (2003), International Diversification Benefits In ASEAN Stock Markets: A Revisit, Economics Working paper, UniversityPutra, Malaysia

Lo, A. and MacKinlay, A.C., 1988, Stock Market Prices Do Not Follow Random Walks: Evidence from a Simple Specification Test, Review of Financial Studies 1, 41-66

Schwert, G. W., 2003, Anomalies and Market Efficiency, Handbook of the Economics of Finance, Chapter 15, 937-972

Worthington, A., and Higgs, H., 2003, Weak-form Market Efficiency in Asian Emerging and Developed Equity Markets: Comparative Tests of Random Walk Behaviour, Working paper series (05/03), University of Wollongong 


\section{ANNEXURE}

\section{Chart A1-A8: Weekly Returns Distribution}
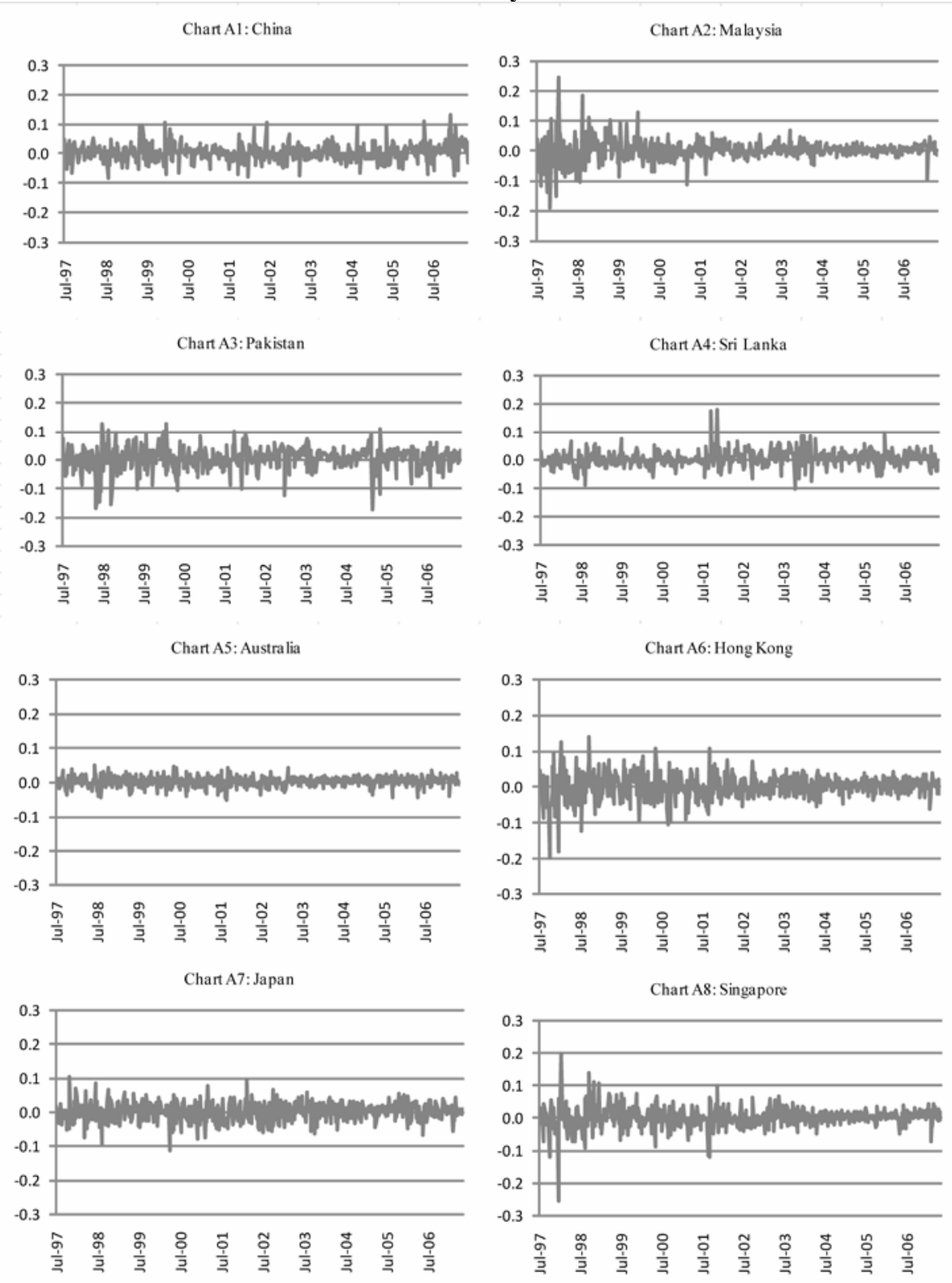
Table A1: Autocorrelations and LJung-Box Q-Statistic-Emerging/Developing

\begin{tabular}{|c|c|c|c|c|c|c|c|c|c|c|c|c|}
\hline \multicolumn{13}{|c|}{ Countries } \\
\hline \multirow[b]{2}{*}{ Lag } & \multicolumn{3}{|c|}{ China } & \multicolumn{3}{|c|}{ Malaysia } & \multicolumn{3}{|c|}{ Pakistan } & \multicolumn{3}{|c|}{ Sri Lanka } \\
\hline & $\mathrm{ACF}$ & Q-Stat & P-Value & ACF & Q-Stat & P-Value & ACF & Q-Stat & P-Value & ACF & Q-Stat & P-Value \\
\hline 1 & 0.06 & 1.89 & 0.16 & 0.04 & 1.03 & 0.31 & $0.17^{*}$ & $15.88^{*}$ & 0.00 & $0.17^{*}$ & $14.93^{*}$ & 0.00 \\
\hline 2 & 0.07 & 4.85 & 0.08 & 0.07 & 4.67 & 0.09 & 0.08 & $19.70 *$ & 0.00 & 0.04 & $15.91 *$ & 0.00 \\
\hline 3 & $0.09^{*}$ & $8.96^{*}$ & 0.03 & 0.06 & 7.27 & 0.06 & 0.00 & $19.71 *$ & 0.00 & 0.07 & $18.23 *$ & 0.00 \\
\hline 4 & 0.04 & $9.74 *$ & 0.04 & 0.03 & 7.91 & 0.09 & -0.02 & $20.04 *$ & 0.00 & 0.02 & $18.38^{*}$ & 0.00 \\
\hline 5 & -0.00 & 9.75 & 0.08 & 0.05 & 9.93 & 0.07 & -0.04 & $21.02 *$ & 0.00 & 0.00 & $18.39^{*}$ & 0.00 \\
\hline 6 & 0.02 & 10.09 & 0.12 & 0.02 & 10.28 & 0.11 & -0.05 & $22.41 *$ & 0.00 & -0.00 & $18.39 *$ & 0.01 \\
\hline 7 & 0.07 & 12.66 & 0.08 & $0.12 *$ & 20.42 & 0.01 & 0.04 & $23.38 *$ & 0.00 & -0.00 & $18.39^{*}$ & 0.01 \\
\hline 8 & 0.02 & 12.83 & 0.11 & 0.00 & $20.42 *$ & 0.01 & 0.02 & $23.60 *$ & 0.00 & 0.01 & $18.45^{*}$ & 0.02 \\
\hline 9 & 0.07 & 15.39 & 0.08 & $0.08^{*}$ & $25.44^{*}$ & 0.00 & 0.01 & $23.61 *$ & 0.00 & -0.06 & $20.44^{*}$ & 0.02 \\
\hline 10 & 0.01 & 15.40 & 0.11 & -0.05 & $27.01 *$ & 0.00 & 0.03 & $24.10^{*}$ & 0.01 & 0.02 & $20.62 *$ & 0.02 \\
\hline $\begin{array}{c}2 / \sqrt{T} \\
* *\end{array}$ & 0.090 & & & 0.076 & & & 0.088 & & & 0.088 & & \\
\hline
\end{tabular}

Table A2: Autocorrelations and LJung-Box Q-Statistic - Developed Countries

\begin{tabular}{|c|c|c|c|c|c|c|c|c|c|c|c|c|}
\hline \multirow[b]{2}{*}{ Lag } & \multicolumn{3}{|c|}{ Australia } & \multicolumn{3}{|c|}{ Hong Kong } & \multicolumn{3}{|c|}{ Japan } & \multicolumn{3}{|c|}{ Singapore } \\
\hline & ACF & Q-Stat & P-Value & ACF & Q-Stat & P-Value & ACF & Q-Stat & P-Value & ACF & Q-Stat & P-Value \\
\hline 1 & $0.19^{*}$ & $44.17 *$ & 0.00 & $0.09 *$ & $8.05^{*}$ & 0.01 & -0.03 & 0.77 & 0.38 & 0.050 & 2.56 & 0.10 \\
\hline 2 & $0.08^{*}$ & $51.74 *$ & 0.00 & $0.07 *$ & $12.91 *$ & 0.00 & 0.06 & 4.85 & 0.08 & 0.027 & 3.31 & 0.19 \\
\hline 3 & 0.02 & $52.43^{*}$ & 0.00 & -0.03 & $13.56^{*}$ & 0.00 & 0.01 & 5.08 & 0.16 & $0.098^{*}$ & $13.18^{*}$ & 0.00 \\
\hline 4 & 0.00 & $52.44 *$ & 0.00 & -0.00 & $13.56^{*}$ & 0.01 & 0.01 & 5.11 & 0.27 & -0.044 & $15.19^{*}$ & 0.00 \\
\hline 5 & -0.04 & $54.71 *$ & 0.00 & -0.04 & $15.48 *$ & 0.01 & 0.02 & 5.71 & 0.33 & 0.007 & $15.24 *$ & 0.01 \\
\hline 6 & -0.00 & $54.76^{*}$ & 0.00 & 0.03 & $16.66^{*}$ & 0.01 & -0.02 & 6.15 & 0.40 & 0.059 & $18.82 *$ & 0.00 \\
\hline 7 & -0.02 & $55.77 *$ & 0.00 & -0.05 & $19.24^{*}$ & 0.01 & 0.05 & 8.77 & 0.27 & 0.047 & $21.08 *$ & 0.00 \\
\hline 8 & -0.05 & $59.45^{*}$ & 0.00 & -0.04 & $20.54^{*}$ & 0.01 & -0.00 & 8.77 & 0.36 & -0.012 & $21.24 *$ & 0.01 \\
\hline 9 & -0.02 & $60.22 *$ & 0.00 & 0.02 & $20.88^{*}$ & 0.01 & 0.03 & 9.69 & 0.37 & 0.012 & $21.39^{*}$ & 0.01 \\
\hline 10 & 0.02 & $61.22 *$ & 0.00 & 0.01 & $20.93 *$ & 0.02 & -0.04 & 11.3 & 0.32 & 0.022 & $21.88^{*}$ & 0.02 \\
\hline $\begin{array}{c}2 / \sqrt{T} \\
* *\end{array}$ & 0.058 & & & 0.061 & & & 0.059 & & & 0.063 & & \\
\hline
\end{tabular}


Stock Market Efficiency and Integration: A Study of Eight Economies in the Asia-Pacific Region

Table A3: Granger Causality Test Results

\begin{tabular}{lccr}
\hline Null Hypothesis & Lag & F-Statistic & Probability \\
\hline DLNMALAY does not Granger Cause DLNCHINA & $\mathbf{2}$ & $\mathbf{3 . 5 8 4 8}$ & $\mathbf{0 . 0 2 8 5}$ \\
DLNCHINA does not Granger Cause DLNMALAY & 2 & 0.2175 & 0.8046 \\
DLNPKSTN does not Granger Cause DLNCHINA & 2 & 1.7712 & 0.1713 \\
DLNCHINA does not Granger Cause DLNPKSTN & 2 & 0.6686 & 0.5129 \\
DLNSL does not Granger Cause DLNCHINA & 2 & 0.6353 & 0.5302 \\
DLNCHINA does not Granger Cause DLNSL & 2 & 2.9044 & 0.0558 \\
DLNPKSTN does not Granger Cause DLNMALAY & 2 & 1.0404 & 0.3540 \\
DLNMALAY does not Granger Cause DLNPKSTN & 2 & 2.1683 & 0.1153 \\
DLNSL does not Granger Cause DLNMALAY & 2 & 0.6904 & 0.5018 \\
DLNMALAY does not Granger Cause DLNSL & $\mathbf{2}$ & $\mathbf{4 . 8 2 8 8}$ & $\mathbf{0 . 0 0 8 3}$ \\
DLNSL does not Granger Cause DLNPKSTN & 2 & 0.4267 & 0.6529 \\
DLNPKSTN does not Granger Cause DLNSL & 2 & 2.6731 & 0.0699 \\
DLNHK does not Granger Cause DLNAUS & 2 & 0.7000 & 0.4970 \\
DLNAUS does not Granger Cause DLNHK & 2 & 0.9508 & 0.3871 \\
DLNJAPAN does not Granger Cause DLNAUS & 2 & 0.5058 & 0.6033 \\
DLNAUS does not Granger Cause DLNJAPAN & 2 & 1.0527 & 0.3497 \\
DLNSIN does not Granger Cause DLNAUS & 2 & 1.2766 & 0.2798 \\
DLNAUS does not Granger Cause DLNSIN & 2 & 0.5520 & 0.5761 \\
DLNJAPAN does not Granger Cause DLNHK & 2 & 0.0416 & 0.9593 \\
DLNHK does not Granger Cause DLNJAPAN & 2 & 1.0059 & 0.3664 \\
DLNSIN does not Granger Cause DLNHK & 2 & 2.3272 & 0.0985 \\
DLNHK does not Granger Cause DLNSIN & $\mathbf{2}$ & $0.9939^{*}$ & $\mathbf{0 . 0 4 5 8}$ \\
DLNSIN does not Granger Cause DLNJAPAN & 2.2097 & 0.7229 \\
DLNJAPAN does not Granger Cause DLNSIN & & & 0.1107 \\
\hline
\end{tabular}

* Significant at $5 \%$ level 